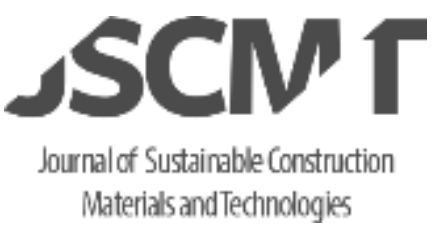

J Sustain. Construct. Mater. Technol. 3(3) (2018) 261-270 \begin{tabular}{c}
\hline \hline Journal of Sustainable \\
Construction Materials \\
and Technologies
\end{tabular}

www.eds.yildiz.edu.tr/jscmt

\title{
Study of the Influence of Fly Ash and Its Content in Marshall Properties of Asphalt Concrete
}

\author{
Niraj Bohara ${ }^{\mathrm{a}}$, Gautam Bir Singh Tamrakar ${ }^{\mathrm{a}, *}$ \\ ${ }^{a}$ Pulchowk Campus, Institute of Engineering, Tribhuvan University, Nepal
}

Manuscript Received July 24, 2018; Accepted October 26, 2018

\begin{abstract}
The study presents possible use of fly ash in asphalt concrete and also an insight on the effect of different fly ash content on Marshall Properties and Optimum Bitumen Content (OBC). Use of a VG-10 grade bitumen was done for the preparation of mix. Four fly ash content, 3\%, 5\%, 7\% and 9\% with varying bitumen contents were prepared and compared with 5\% cement mix and 5\% stone dust mix.

Consideration of filler content in mix design is very important. At different filler contents asphalt concrete mixes behave differently. Marshall Stability of mix increase with the increase in filler content at OBC. However, stability only increase till $7 \%$ fly ash content. With more inclusion of fly ash in the mix, stability decreases. A maximum stability of $15.88 \mathrm{kN}$ is observed at $7 \%$ fly ash content at $6.30 \% \mathrm{OBC}$. In contrast to that, mixes become less flexible when filler content is increased in mix (mixes show lower flow value). Thus, increased viscosity (as shown from increased flow value) results in increase in $\mathrm{OBC}$ with increase in fly ash content. Additionally, mixes with fly ash behaves superiorly when compared to other conventional mix. Fly ash mix at $7 \%$ content at OBC, though with high cost is economically feasible and superior in physical characteristics (in the case, Marshall properties) compared to other fly ash content mix and cement mix.
\end{abstract}

Keywords:Marshall stability; Flow Value; Fly Ash; Cement; Stone Dust, Cost

\section{Introduction}

Nepal is one of the least developed country with a least developed transportation network. As per the statistics provided by the Department of Road, only $54 \%$ of $13,086.46 \mathrm{~km}$ length of the Strategic Road Network (Department of Road, 2015) and a mere 3.5\% under Department of Local Infrastructure Development and Agricultural Roads (DoLIDAR) of total 57,632 km are paved [1]. With reference to World Bank [2] report, the country has less than $10 \%$ of roads maintained as asphalt concrete. The report also presented the ineffectiveness on implementing policy regarding the provision for surface treatment with asphalt concrete which are required for the high voluminous road.

Asphalt concrete is one of the robust form of pavement. The main component of the asphalt concrete includes coarser and granular aggregates, bitumen and filler materials. Bitumen and filler materials together acts as binder in the mix. Fillers are responsible for facilitating easy coating, paving, compaction and providing the mix with sufficient viscosity resulting in production of final lesser void and water-resistant mix. [3] [4] Fillers are finer materials where minimum of 70\% passes through No. 200 sieve (75 $\mu$ ) as per ASTM-D242, [5].

\footnotetext{
${ }^{\text {a }}$ Corresponding author:

E-mail: 072mst258@pcampus.edu.np (G.B.S. Tamrakar)
}

https://doi.org/10.29187/jscmt.2018.29 


\subsection{Asphalt Concrete behavior with different fillers}

ASTM-D242, a Standard Specification for Mineral Filler for Bituminous Paving Mixtures, defines fly ash, rock dust, hydrated lime, hydraulic cement, loess, slag dust as possible mineral fillers. But presently in Nepal, only stone dust obtained from local quarries is being used as filler without any researches for other fillers. Many studies have suggested that different fillers impart different properties in mix. On a study by Mistry \& Roy [6] of the hydrated lime and fly ash fillers for asphalt concrete, Marshall Quotient of mix with fly ash and hydrated lime as the fillers varied even at the same bitumen and fillers content. This is illustrated in the graph, Fig 1.

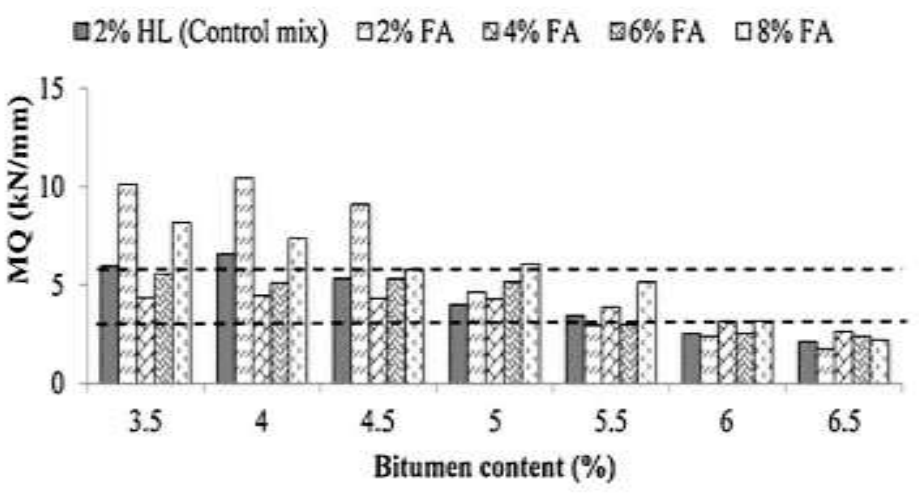

Fig. 1. Marshall Quotient's comparison of different fly ash content and 2\% hydrated lime containing mix. [6]

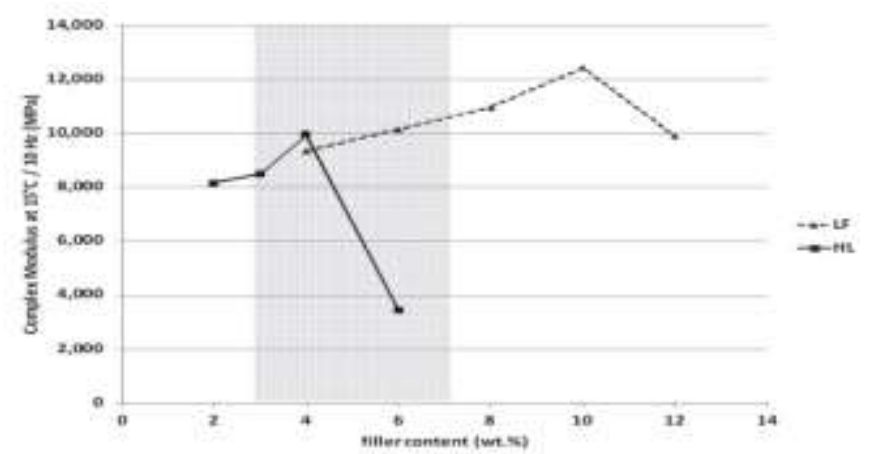

Fig. 2 Two different peaks for two different kinds of fillers in the mix. [7]

The work from Didier Lesueur et al [7] showed the effect of hydrated lime and limestone filler in terms of complex modulus of mix. Peak complex modulus was observed at $4 \%$ by weight in hydrated lime mix whereas at $10 \%$ by weight in case of limestone filler as in Fig 2.

\subsection{Coal fly ash}

Coal fly ash; a coal combusted product which is produced after combustion of coal in steam generating electricity plants, is regarded as waste. It essentially consists of slilicon dioxide, aluminum oxide, iron oxide and calcium oxide. The Standard Specification of Roads and Bridge Works, 2015 (SSRBW), [8], for Nepal has failed to specify fly ash as the possible filler in asphalt concrete. As per American Coal Ash Association, for finer and lower specific gravity fly ashes (of range 2.0 to 2.6), the requirement of percentage by weight of filler to produce similar properties (in reference to the stiffness of mix) mix is lesser and hence is cost effective [9]. As per Hesami [3], asphalt mastic, bitumen and fillers in combine, doesn't lose its viscosity in considerable amount upon addition of fly ash in the mix. As mixes are prepared to confirm viscosity of bitumen during mixing and compaction, not so considerable loss in viscosity of the mix allows in confirming to the selected mixing and compaction temperature obtained from the viscosity-temperature chart of bitumen itself. This is due to the tiny roller like spherical particles which helps in decreasing friction in mix and thus increasing density with lesser voids. [10] 


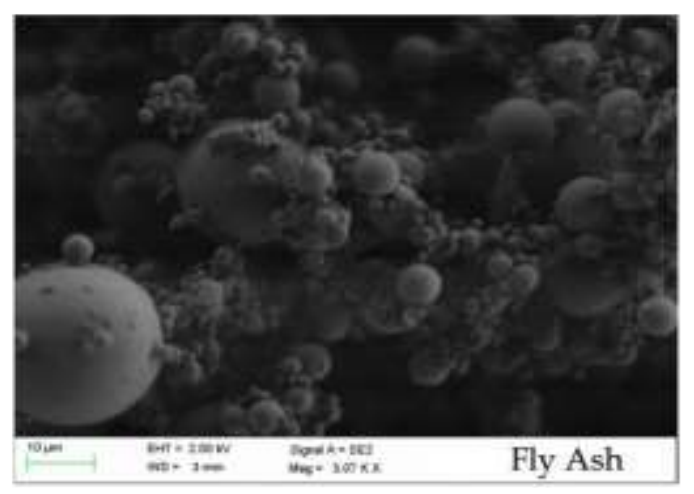

Fig. 3 Scanning Electronic Microscope image showing spherical roller like particles of fly ash, [3]

Bautista et al explained the dominance of fly ash over limestone fillers in the stiffening of asphalt mastics because of chemical composition and physical properties of fly ash filler. Other properties such as rheological properties, aging resistance, rutting resistance, grade improvement of bitumen, possible asphalt extender and crack arresting behaviors are also induced with fly ash inclusion in asphalt mastics. [11] Modarres \& Rahmanzadeh observed highest stability of $1260 \mathrm{~kg}$ for $7 \%$ of coal waste ash by total weight of aggregate when compared to mix of limestone, coal waste powder and other different mix filler proportions. [12] Mistry \& Roy found out peak stability at $6 \%$ fly ash content. [6] The mix with fly ash also showed higher stability compared to the mix with hydrated lime filler. Optimum Bitumen Content obtained for mix with fly ash as filler also were lower when compared to the control mix. Abdelrazig et al also observed highest stability of $1923 \mathrm{~kg}$ at $5 \%$ OBC for fly ash in contrast to $1527 \mathrm{~kg}$ stability with limestone filler at 5.5\% OBC [13].

The tests were also taken to field by Sobolev et al, where the mix with certain quantity of bitumen being replaced with fly ash showed enhanced results for Falling Weight Deflectometer test when compared with pavement without fly ash fillers. [14] Schroeder, for a test section of $230 \mathrm{~m}$ length with fillers of mix $11 \%$ fly ash and 5\% hydrated lime, observed significant lower rutting than the control section. [15]

\subsection{Cement and stone dust}

\subsubsection{Cement}

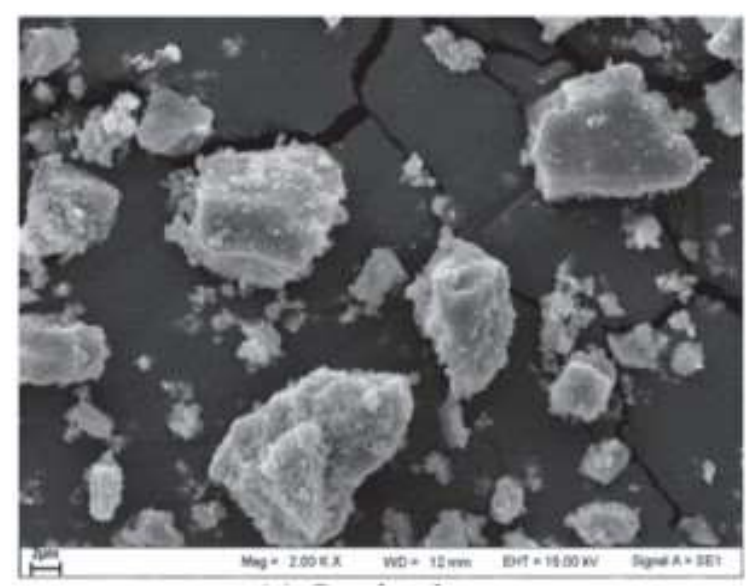

Fig. 4 Scanning Electronic Microscope image of cement grains, [10]

Cement is one of the high specific gravity finer material which can be used as a mineral filler in asphalt concrete. Cement has been accepted as one of mineral fillers in standards as ASTM-D242 ([5]) and specification of work for Nepal (SSRBW), [8]. The fineness of cement allows the voids to get filled in the mix thus producing stiffer mix. Likitlersuang \& Chompoorat [10] provided evidence of stiffening effect, reduction in permanent deformation (rutting resistance) and moisture resisting nature with cement /and or fly ash as fillers in the mix. A Scanning Electronic Microscope (SEM) image of the cement is shown in Fig 4 which shows irregular nature of the cement grains which are finer than fly ash particles [10]. 


\subsubsection{Stone dust}

Rock dust are most common fillers in use in the world for asphalt concrete. These can satisfy requirements for mineral fillers (fineness, plasticity index) and are available easily from most quarries. Nepal, with its varying geological nature, is very rich in its mineral composition as discussed in a report "Geology and Mineral Resources of Nepal - An overview by K.M. Amatya under Department of Mines and Geology, [16]. With the presence of different composition of minerals in different parts of Nepal, the chemical differences in parent rocks provides a varying quality and nature of rock fillers. This ultimately effects the physical properties of asphalt mix.

As per study by Chandra, Kumar \& Feyissa [17], higher performance was observed for marble dust over conventional fillers stone dust and limestone dust. Bhatt \& Mittal [18] also studied the effect of brick dust and concrete dust and observed their positive effect in asphalt concrete. Thus, the nature of stone-dust obtained effects the properties of mix and the quality.

\subsection{Rationale of the study}

Much more importance is given to the design of aggregate gradation, limits of aggregate strengths and more importantly, the bitumen content in construction field herein Nepal. However, many studies, above mentioned, have suggested the importance of filler contents and its quality in achieving required asphalt concrete's property. In addition to that, achieving required stiffness of mix within reasonable cost is also important. Thus, use of ecofriendly, economically sustainable technology along with use of sustainable materials (wastage materials) are nowadays needs. To that context, fly ash are being preferred as construction material and are even getting attention for use in asphalt concrete.

The present study would thus suggest use of fly ash, a waste product, in asphalt concrete and its influences in performance of asphalt concrete along with the cost aspects associated with it.

\section{Methodology}

The analysis of different composition of filler and different types of filler needed a standard procedure for producing an appropriate result. As per the available resources, standard Marshall Stability tests as per ASTM D6926, ([19]), D6927, ([20]) and Standard Specification for Road and Bridge Works (SSRBW), ([8]) were performed and taken for analysis of different mix.

\subsection{Selection of aggregate}

Three aggregate groups were collected from Tikabhairav quarry (in Lalitpur, nearest quarry site) to meet up the gradation requirement provided by SSRBW. Aggregate sieve analysis along with job mix design are referred in Table 1. The resultant gradation formed is given in graph in Fig 5.

The specific gravity of three sets of aggregates are:

$$
\begin{aligned}
& \text { A1 }=2.75 \\
& \text { A2 }=2.70 \\
& \text { A3 }=2.59
\end{aligned}
$$

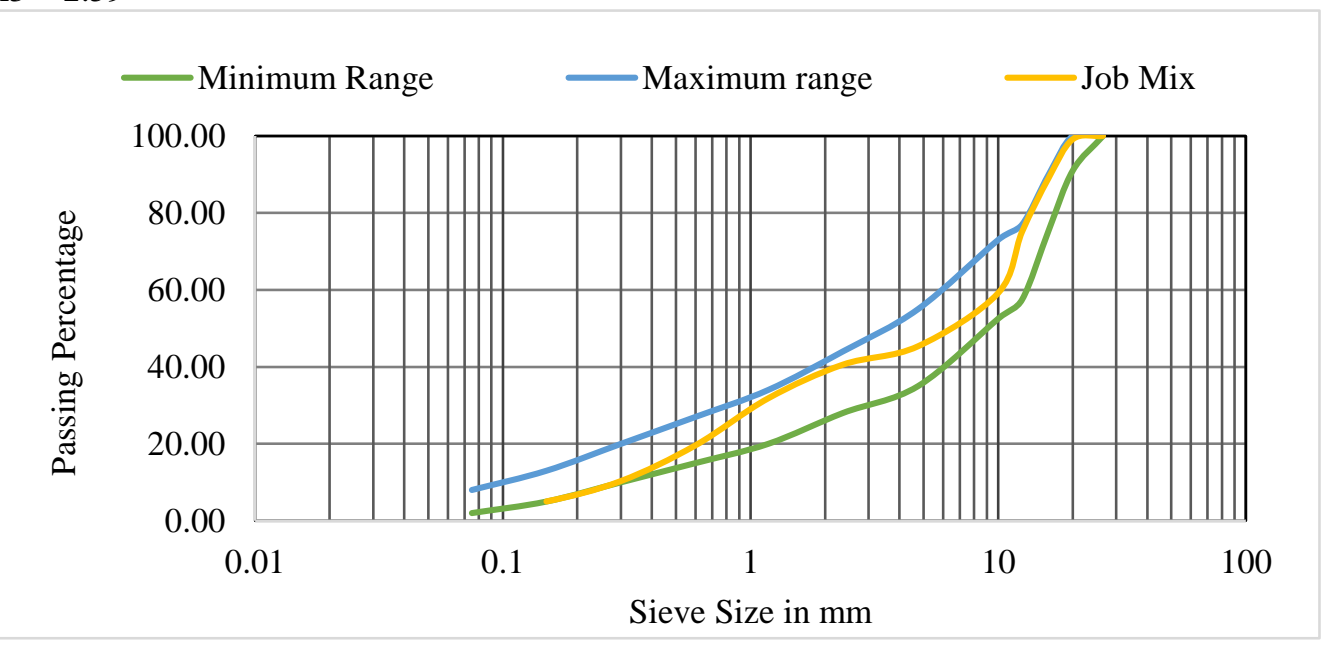

Fig. 5 Limiting aggregate gradation and selected aggregate gradation 
Destructive tests performed on coarser aggregate $\mathrm{A}_{1}$ resulted in following results:

Los Angles Abrasion Value (LAA) $=30 \%$

Aggregate Impact Value (AIV) $=19 \%$

Aggregate Crushing Value $(\mathrm{ACV})=21 \%$

As per recommendations by SSRBW, LAA value should not be greater than $30 \%$ and ACV should not be greater than $24 \%$. Thus, the selected aggregate satisfied requirement of aggregate for asphalt concrete.

Table 1. Job mix design of aggregate as per the limits specified by Standard Specification for Road and Bridge Works, Department of Road, Nepal

\begin{tabular}{lllllll}
\hline & $\begin{array}{l}\text { Aggregate }_{1} \\
\text { Coarser }\end{array}$ & $\begin{array}{l}\text { Aggregate } \\
\text { Dust }\end{array}$ & $\begin{array}{l}\text { Aggregate }_{3} \\
\text { Dust }\end{array}$ & & & \\
Proportion $(\rightarrow)$ & $50 \%$ & $36 \%$ & $18 \%$ & & Limits \\
Sieve $(\mathrm{mm})(\downarrow)$ & $(26.5$ to & $(16-0.075)$ & $\begin{array}{l}\text { Passing } \\
1.18\end{array}$ & $\begin{array}{l}\text { Passing } \\
(\%)\end{array}$ & $\begin{array}{l}\text { Lower } \\
\text { Upper }\end{array}$ \\
& $1.18)$ & & 100.00 & 100.00 & 100.00 & 100.00 \\
\hline 26.5 & 100.00 & 100.00 & 100.00 & 99.17 & 91.00 & 100.00 \\
20 & 98.33 & 100.00 & 100.00 & 89.15 & 75.50 & 90.00 \\
16 & 78.30 & 100.00 & 100.00 & 75.17 & 57.50 & 77.00 \\
12.5 & 50.75 & 99.37 & 100.00 & 59.18 & 52.50 & 73.00 \\
10 & 18.53 & 99.75 & 100.00 & 45.35 & 35.00 & 55.00 \\
4.75 & 2.34 & 81.82 & 100.00 & 40.58 & 28.00 & 44.00 \\
2.36 & 1.34 & 68.46 & 100.00 & 31.84 & 20.00 & 34.00 \\
1.18 & 0.00 & 43.26 & 61.14 & 19.62 & 15.00 & 27.00 \\
0.6 & 0.00 & 26.92 & 31.63 & 10.33 & 10.00 & 20.00 \\
0.3 & 0.00 & 14.5 & 14.76 & 5.03 & 5.00 & 13.00 \\
0.15 & 0.00 & 7.41 & 6.63 & 2.47 & 2.00 & 8.00 \\
0.075 & 0.00 & 3.99 & & & & \\
\hline
\end{tabular}

\subsection{Selection of binder}

As per Standard Specification for Road and Bridge Works, Department of Road, Nepal (SSRBW) and known sets of experiment, the selected bitumen from nearest local contractor was identified as VG-10 bitumen. However, the selected bitumen had a very low penetration index of -2.15 . Other tested properties of selected bitumen are provided in the Table 2.

Table 2. Tests performed on selected bitumen

\begin{tabular}{llll}
\hline S.N & Tests & Standard & Observed Value \\
\hline i. & Penetration at $25^{\circ} \mathrm{C}, 100 \mathrm{~g}, 5 \mathrm{~s}, 0.1 \mathrm{~mm}$ & IS 1203 & 100 \\
ii. & Absolute viscosity at $60^{\circ} \mathrm{C}$, Poise & IS 1206 part 2 & 825.8 \\
iii. & Softening point (Ring \& Ball), ${ }^{\circ} \mathrm{C}$ & IS 1205 & 41 \\
iv. & Ductility at $25^{\circ} \mathrm{C}, \mathrm{cm}$ & IS 1208 & $>100$ \\
v. & Specific gravity & IS1202 & 1.002 \\
\hline
\end{tabular}

\subsection{Selection of fillers}

Three different types of fillers were selected to study the effect of fillers. Fly ash with a specific gravity 2.15 was selected which was brought from Butwol Cement (Bhairhawa, Nepal) factory, a product of Electric Power plant of Deoria, India. Pozzolana Portland Cement from local hardware store for cement filler with a specific gravity of 2.95 was collected. Similarly, for stone dust, dust prepared from the same source of aggregate passing from $75 \mu$ size sieve was collected with specific gravity of 2.63 (with presence of larger proportions of limestone). 
Table 3. Sieve analysis of Fly Ash

\begin{tabular}{ll}
\hline $\begin{array}{l}\text { Sieve Size } \\
(\mathrm{mm})\end{array}$ & $\begin{array}{l}\text { Percentage Passing } \\
(\%)\end{array}$ \\
\hline 0.3 & 100 \\
0.15. & 97 \\
0.075 & 83
\end{tabular}

As fly ash is not included in the specification for norms of work for asphalt pavement, it was important to check for other properties. Gradation was performed and the result did not match with requirement specified by SSRBW. However, satisfied gradation requirement provided by ASTM D242 (Standard specification for mineral filler for bituminous paving mixtures) which requires only $70 \%$ of particles to be finer than $75 \mu$ instead of $85 \%$ provided by SSRBW. Thus, there is a need for the revision of standards for newer filler materials like fly ash herein Nepal

\subsection{Specimen preparation and testing}

All together sixty-nine (69) Marshall specimens including control specimens (for comparison) were prepared. Control specimens consisted three specimens with 5\% cement content and three specimens with $5 \%$ of stone dust as fillers by weight of aggregate with $6 \%$ of binder content. Other samples with varying amount of fly ash content and binder content to obtain an optimum filler content and optimum binder content by weight were prepared. The Table 4 shows specimens prepared during tests with different contents of fillers and binders. Specimens were prepared confirming to ASTM-D6926 \& ASTM-D6927 ([20], [19]) and tested for stability and flow value as for comparison.

For the selection of mixing and compaction temperature, with the known sets of the bitumen's experiment result, temperatures at corresponding viscosity of $170 \pm 20$ cPoise and $280 \pm 30 \mathrm{cPoise}$ as $\left(135-138^{\circ} \mathrm{C}\right)$ and $(125$ $-130^{\circ} \mathrm{C}$ ) were selected with the help of Bitumen Test Data Chart. [21], The Bitumen Test Data Chart is shown in Fig 6.

Table 4. Different specimens with their filler content and binder content

\begin{tabular}{ll}
\hline $\begin{array}{l}\text { Filler Type } \\
\text { \& Content }\end{array}$ & $\begin{array}{l}\text { Binder Content } \\
(\%)\end{array}$ \\
\hline 3\% Fly Ash & $4.5,5,5.5,6,6.5,7$ \\
5\% Fly Ash & $5,5.5,6,6.5,7$ \\
$7 \%$ Fly Ash & $5,5.5,6,6.5,7$ \\
9\% Fly Ash & $5,5.5,6,6.5,7$ \\
5\% Stone dust & 6 \\
5\% Cement & 6 \\
\hline
\end{tabular}

\subsection{Cost analysis}

Based on unit weight of different mix obtained from tests, unit rate obtained from district rate of Kathmandu, 2017, unit rate of importing fly ash from India, norms for unit rate given by Department of Road for paving and laying asphalt concrete, the unit cost of paving unit $\mathrm{m}^{3}$ of asphalt concrete with different fillers at Optimum Bitumen Content are calculated. The unit cost is used as a base to analyze and recommend preferable mix for producing better mix in context of Nepal.

\section{Result and Discussion}

\subsection{Marshall properties}

All sixty-nine specimens Marshall tests can be summarized as:

1. With the increase in the filler content with same bitumen content, the Marshall stability increase whilst flow value decrease.

2. At lower bitumen content, usually smaller than $6 \%$ bitumen content, with the increase in filler content, percentage of air voids and voids in mineral aggregate (VMA) decrease.

3. At higher bitumen content, usually for more than $6 \%$, the void content is lower than that for higher filler content 
because of the predominating character of bitumen at lower filler content. The behavior could be taken, where the mix shows greater influence of bitumen at higher bitumen content where despite bearing low air void content, the mix shows higher flexibility (flow value) with low Marshall stability

4. The maximum stability of $17.2 \mathrm{kN}$ is observed at $9 \%$ fly ash content at $6 \%$ bitumen content.

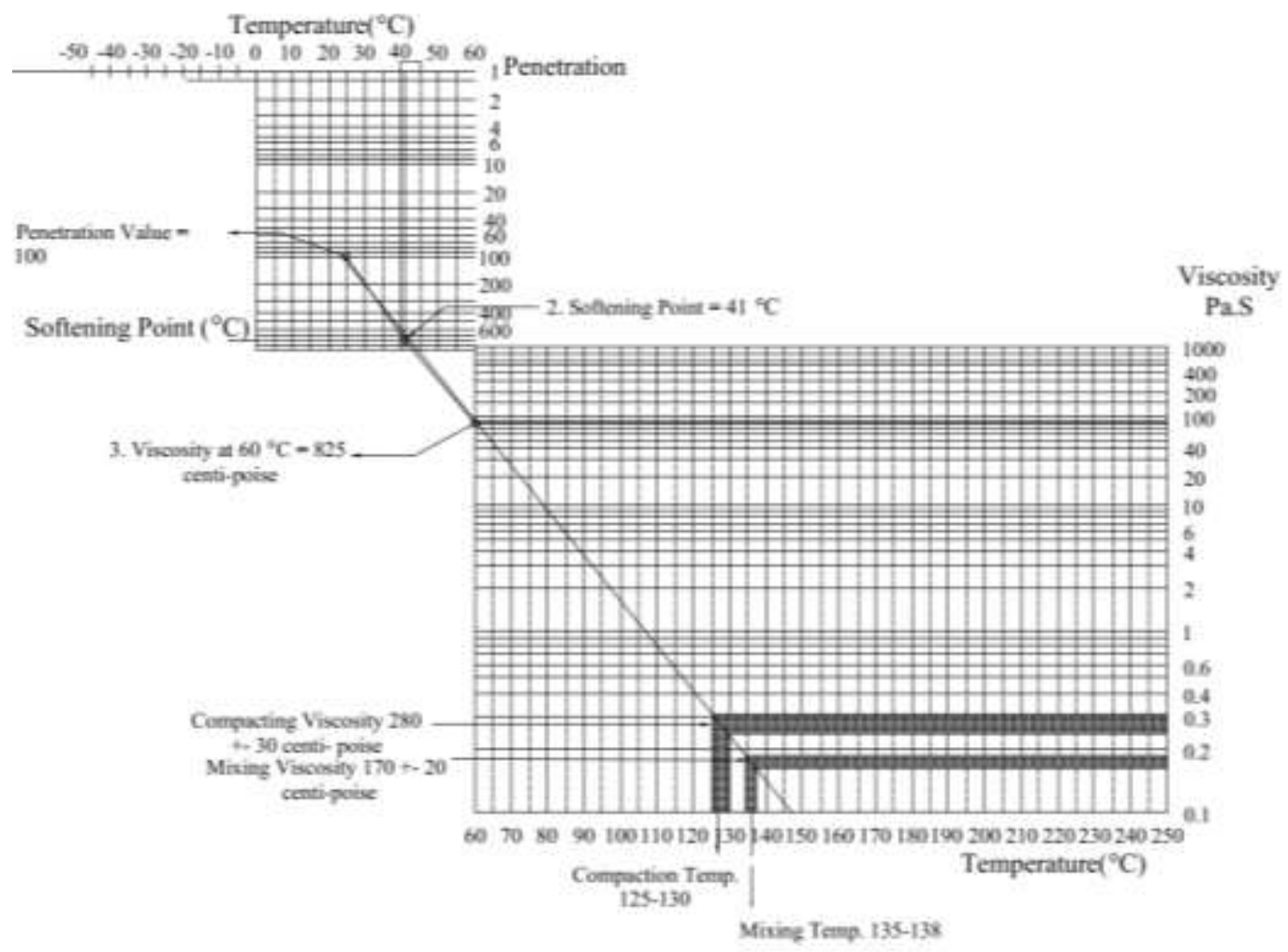

Fig. 6 Bitumen Test Data Chart, mixing and compaction temperature

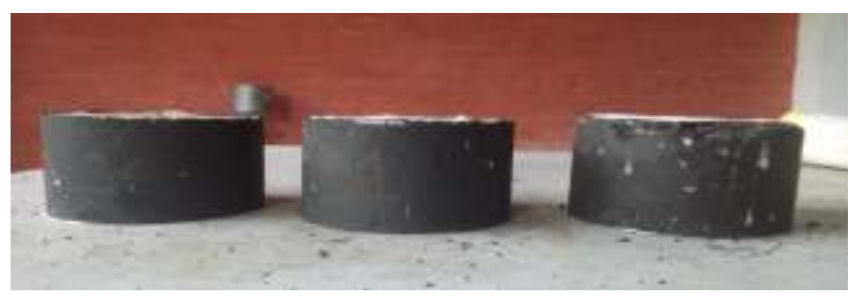

Fig. 7 Specimens containing 7\% fly ash with varying bitumen content, 7\%, 6.5\% and 6\% bitumen content

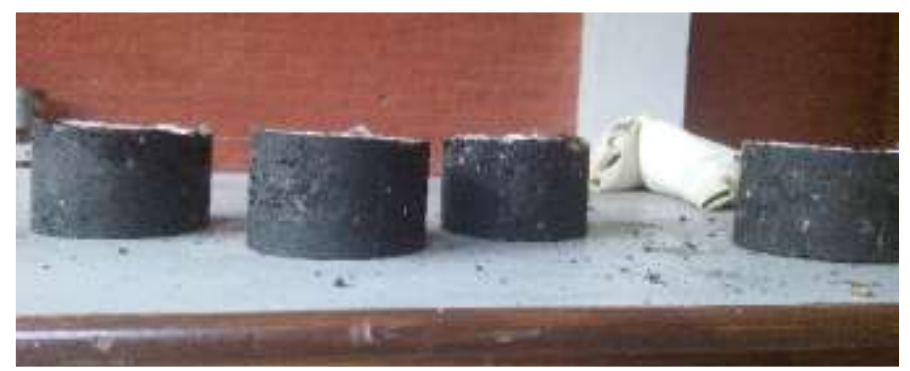

Fig 8. Two specimens on the left containing cement fillers at $6 \%$ bitumen content and remaining specimen contains stone dust filler 


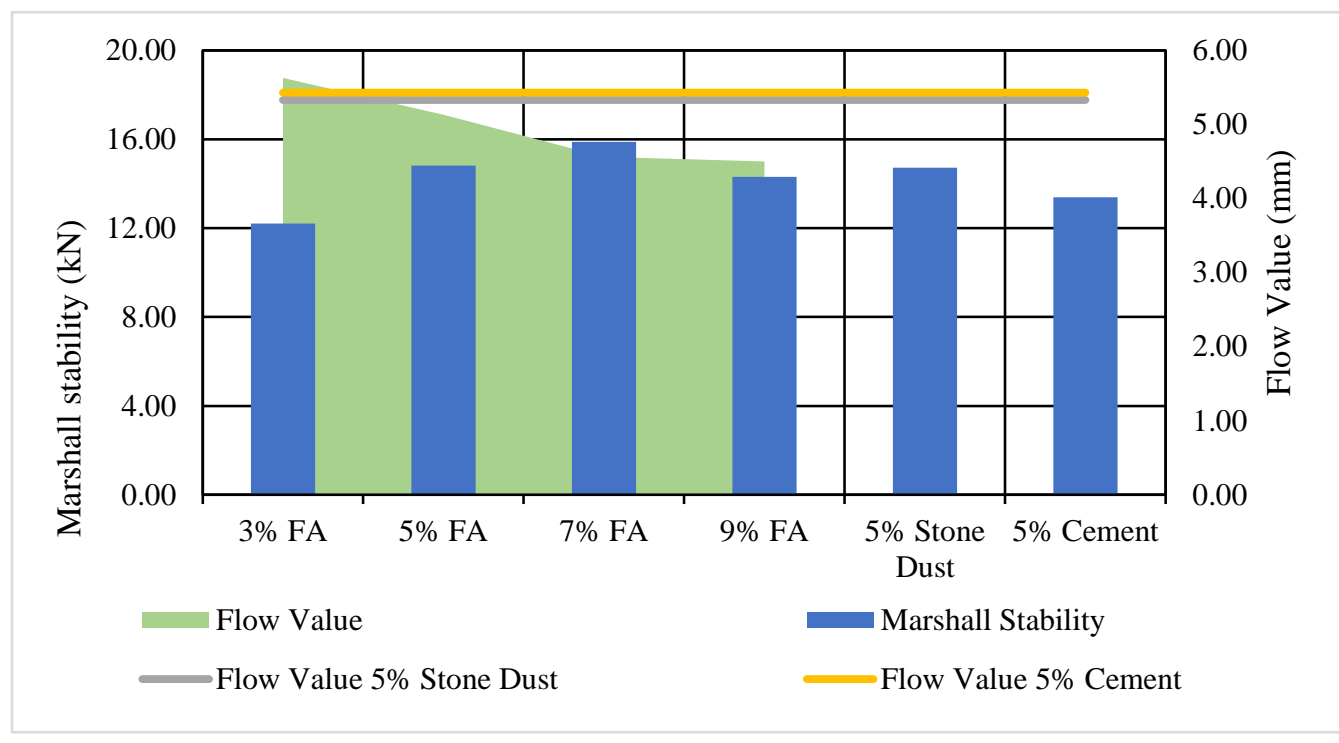

Fig. 9 Marshall stability and flow value for different mix at OBC

With all set of Marshall test results, optimum bitumen content was calculated as an average of bitumen content for maximum unit weight of mix, for $4 \%$ of air voids and maximum Marshall Stability. The result is summarized in Table 5 where VMA means Voids in Mineral Aggregate, VFB means Voids Filled with Bitumen., FA means fly ash and BC refers bitumen content.

Table 5. Marshall properties at Optimum Bitumen Content

\begin{tabular}{|c|c|c|c|c|c|c|c|c|}
\hline Filler content & $\begin{array}{l}\text { OBC. } \\
\text { Binder Content } \\
\%\end{array}$ & $\begin{array}{l}\text { Unit Wt } \\
\mathrm{gm} / \mathrm{cm}^{3}\end{array}$ & $\begin{array}{l}\% \text { of } \\
\text { Air } \\
\text { Voids }\end{array}$ & $\begin{array}{l}\text { VMA } \\
\%\end{array}$ & $\begin{array}{l}\text { VFB } \\
\%\end{array}$ & $\begin{array}{l}\text { Marshall } \\
\text { Stability } \\
\mathrm{kN}\end{array}$ & $\begin{array}{l}\text { Flow } \\
\text { Value } \\
\text { mm }\end{array}$ & $\begin{array}{l}\text { Marshall } \\
\text { Quotient } \\
\text { kN/mm }\end{array}$ \\
\hline $3 \% \mathrm{FA}$ & $6.10 \%$ & 2.299 & 5.44 & 19.42 & 72.05 & 12.21 & 5.63 & 2.169 \\
\hline $5 \% \mathrm{FA}$ & $6.29 \%$ & 2.300 & 4.66 & 18.94 & 75.57 & 14.81 & 5.13 & 2.887 \\
\hline $7 \% \mathrm{FA}$ & $6.3 \%$ & 2.290 & 4.74 & 19.10 & 75.51 & 15.88 & 4.56 & 3.479 \\
\hline $9 \% \mathrm{FA}$ & $6.5 \%$ & 2.276 & 4.62 & 19.37 & 76.26 & 14.30 & 4.50 & 3.179 \\
\hline $5 \%$ Stone dust & $6 \% \mathrm{BC}$ & 2.316 & 5.41 & 19.38 & 72.23 & 14.71 & 5.33 & 2.759 \\
\hline $5 \%$ Cement & $6 \% \mathrm{BC}$ & 2.309 & 6.26 & 19.71 & 69.37 & 13.39 & 5.43 & 2.465 \\
\hline
\end{tabular}

The inclusion of filler in the mix increases need of bitumen for maintaining higher stability. Thus, with increase in fly ash content from 3\% to 9\%, Optimum Bitumen Content increase from $6.10 \%$ to $6.50 \%$ where a minimum difference is observed between 5\% and 7\% fly ash content mix. Similar to the observation of peak by Lesueur [7] for stiffening properties, the experiment also observed a peak stability of $15.88 \mathrm{kN}$ at $6.30 \%$ bitumen content (OBC) for $7 \%$ fly ash content which also can be seen in Fig 9 as a tallest bar. Similarly, lower flow value for higher filler content is observed which signifies can direct to the idea of increasing viscosity of mix along with inclusion of fillers in mixes.

All fly ash containing mixes seem to perform better than control mixes (cement and stone-dust) in terms of flow value, Marshall stability and Marshall quotient except for the mix of $3 \%$ fly ash containing mix. It also signifies the importance of design of filler contents in mix to obtain required properties.

\subsection{Cost Analysis}

The norms for unit rate given by Department of Road for paving and laying of asphalt concrete provides quantity of different materials required in different headings (as provided in Table 6). However, the material quantity such as aggregate, bitumen and filler in asphalt concrete depends upon the finished proportions of respective materials. Thus, material estimate is performed based on unit weight of mix, proportions of different materials (filler-aggregate ratio, bitumen content) and an extra 10\% loss. Since, fly ash has to be imported from 
India, unit cost of fly ash is calculated including its unit cost, custom duty charge (section 26 of list of tariff as custom duty) and corresponding freight charge which came to be NPR 3.93 per kg. Similarly, NPR 2851.46 for 1 $\mathrm{m}^{3}$ for aggregate and NPR 15.94 per kg for cement were taken as unit cost for the estimate respectively.

It is evident from Table 6 that with the increase of fly ash content, the cost of mix increases. But the increase in not drastic with respect to the fly ash content. This is due to the cost of bitumen which has a major share on the cost in paving and laying of asphalt concrete. Optimum Bitumen Content at 5\% and 7\% fly ash contents are nearly same which is also seen in the cost of paving and laying per $\mathrm{m}^{3}$ of asphalt concrete.

Though, fly ash has to be imported from India (where it is regarded as a waste), cost of asphalt concrete with fly ash are still smaller than that of cement containing asphalt concrete. And, cost contribution by filler contents in asphalt concrete mixes are found to be $1.52 \%, 2.47 \%, 3.43 \%$ and $4.29 \%$ for $3 \%, 5 \%$, $7 \%$ and $9 \%$ fly ash mix respectively whereas a mere $1.10 \%$ cost contribution for stone-dust asphalt concrete mix is observed.

Table 6. Unit cost of paving $1 \mathrm{~m}^{3}$ of asphalt concrete with different fillers

\begin{tabular}{llllllll}
\hline SN & Material & \multicolumn{7}{l}{ Cost in NPR } \\
\cline { 3 - 8 } & & $3 \%$ FA & $5 \%$ FA & $7 \%$ FA & $9 \%$ FA & $\begin{array}{l}5 \% \text { Stone- } \\
\text { dust }\end{array}$ & $\begin{array}{l}5 \% \\
\text { Cement }\end{array}$ \\
\hline 1 & Manpower & 107.6 & 107.6 & 107.6 & 107.6 & 107.6 & 107.6 \\
2 & Aggregate & $3,980.63$ & $3,892.36$ & $3,793.44$ & $3,681.30$ & $3,931.57$ & $3,920.25$ \\
3 & Filler & 280.14 & 466.16 & 649.72 & 828.47 & 200.84 & $1,730.11$ \\
4 & Bitumen & $10,489.88$ & $10,821.32$ & $10,791.4$ & $11,065.91$ & $10,394.21$ & $10,364.29$ \\
5 & Other Material & $1,134.43$ & $1,134.43$ & $1,134.43$ & $1,134.43$ & $1,134.43$ & $1,134.43$ \\
6 & Heavy Equipment & $2,474.96$ & $2,474.96$ & $2,474.96$ & $2,474.96$ & $2,474.96$ & $2,474.96$ \\
Total & & $18,467.63$ & $18,896.82$ & $18,951.54$ & $19,292.66$ & $18,243.60$ & $19,731.63$ \\
Cost contribution of fillers & $1.52 \%$ & $2.47 \%$ & $3.43 \%$ & $4.29 \%$ & $1.10 \%$ & $8.77 \%$ \\
\hline
\end{tabular}

\section{Conclusion}

- The study depicted importance of filler contents in the performance of asphalt concrete if all other properties are retained same. If filler contents are less, less stiff the mixes become whereas if filler contents are high, higher is the requirement of bitumen which ultimately increase the cost of mix. So, an optimum filler content is required to achieve stiffer and economical mix.

- At $7 \%$ fly ash content with $6.30 \%$ optimum bitumen content, asphalt concrete mix behaves superiorly and also is economically viable when compared to mix with cement as filler. Thus, the study recommends $7 \%$ fly ash content as economically feasible mix. (with respect to Marshall properties)

- The mix with fly ash at optimum binder content outperforms the control mix with cement and stone dust.

- With the inclusion of fly ash in mix, there is decrease in flow value referring to its increased viscosity which in turn increases the requirement for bitumen to obtain optimum performance (Maximum stability, maximum unit weight and optimum air void content).

Thus, fly ash could be one of the suitable substitute of filler materials for achieving stiffer (higher stability and lower flow value) asphalt concrete mix herein Nepal with an addition of minimal cost.

\section{Acknowledgement}

We would like to express their gratitude to Pulchowk Engineering Campus, Institute of Engineering, Pulchowk, Lalitpur, Kantipur Engineering College, Dhapakhel, Lalitpur and Central Laboratory of Department of Road, Pulchowk, Lalitpur for providing constant support through laboratory works required for the study. Similarly, we would also like to acknowledge the continuous support and motivation from friends, family and all the seniors throughout the study.

\section{References}

1. DoLIDAR, Statistics of local road network (SLRN), 2016, Tech. rep. (2016)

2. World Bank, Nepal road sector assessment study, Tech. rep. (2012). 
3. E. Hesami, Characterisation and modelling of asphalt mastic and their effect on workability (PhD dissertation), Tech. rep., Division of Highway and Railway Engineering, Stockholm, Stockholm (2014)

4. F. P. Jimenez, R. M. Recasens, A. Mart ' 'inez, Effect of filler nature and content, Road Materials and Pavement Design 9 (1) (2008) 417-431.

5. ASTM, Standard specification for mineral filler for bituminous paving mixtures, Tech. rep. (2000).

6. R. Mistry, T. K. Roy, Effect of using fly ash as alternative filler in hot mix asphalt, Perspectives in Science 8 (2016) 307-309.

7. D. Lesueur, M. L. Blazquez, D. A. Garcia, A. R. Rubio, On the impact of the filler on the complex ' modulus of asphalt mixtures, Road Materials and Pavement Design (2017) 1-15.

8. DoR, Standard specification for road and bridge works, Tech. rep. (2015).

9. American Coal Ash Association, Fly ash facts for highway engineers, Tech. rep. (2003).

10. S. Likitlersuang, T. Chompoorat, Laboratory investigation of the performances of cement and fly ash modified asphalt concrete mixtures, International Journal of Pavement Research and Technology 9 (5) (2016) 337-344.

11. E. G. Bautista, J. Flickinger, R. Saha, I. Flores-Vivian, A. F. Faheem, K. Sobolev, Effect of coal combustion products on high temperature performance of asphalt mastics, Construction and Building Materials 94 (1) (2015) 572-578

12. A. Modarres, M. Rahmanzadeh, Application of coal waste powder as filler in hot mix asphalt, Construction and Building Materials 66 (2014) 476-483.

13. A. H. Abdelrazig, S. A. Osman, A. A. M. Elhassan, The influence of fly ash on the engineering properties of asphalt and hot mix asphalt, International Journal of Pavement Research and Technology 4 (2) (2016) 109-116.

14. K. Sobolev, I. Flores, J. D. Bohler, A. Faheem, A. Covi, Application of fly ash in asphalt concrete: from challenges to oppurtunities, Tech. rep., Department of Civil Engineering and Mechanics, University of Wisconsin-Milwaukee; Bloom Companies; Department of Civil Engineering, University of Wisconsin -Plattevilel; We Energies (2013).

15. R. L. Schroeder, The use of recycled materials in highway construction, Tech. rep., U.S. Department of Transportation/ Federal Highway Administration (1994).

16. K. Amatya, Geology and mineral resources of Nepal - An overview, Tech. rep., Department of Mines and Geology, Kathmandu, Nepal (1995).

17. S. Chandra, P. Kumar, B. A. Feyissa, Use of marble dust in road construction, Road Materials and Pavement Design 3 (2002) 317-330.

18. M. A. Bhatt, O. Mittal, Effect of fillers on bituminous mixes, International Journal of Advanced Research in Education \& Technology 3 (2).

19. ASTM-D6926, Standard practice for preparation of bituminous specimens using Marshall apparatus, Tech. rep. (2010).

20. ASTM-D6927, Standard test method for Marshall stability and flow of bituminous mixtures, Tech. rep. (2006). 